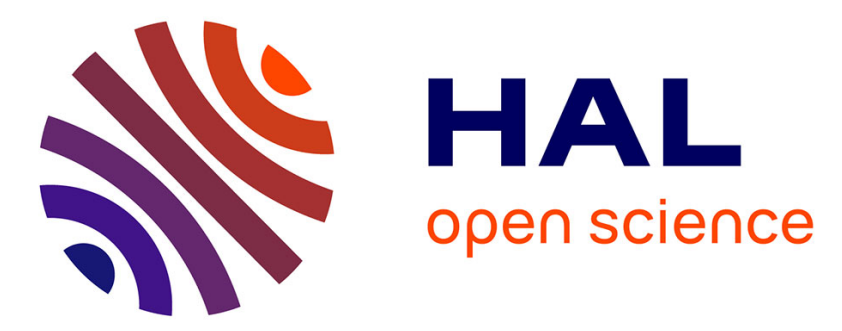

\title{
Scenarios for the Development of Platform-Based Networks for Additive Spare Part Production
} Jana Frank, Philipp Jussen, Lennard Holst, Timo Lütke Meyring

\section{To cite this version:}

Jana Frank, Philipp Jussen, Lennard Holst, Timo Lütke Meyring. Scenarios for the Development of Platform-Based Networks for Additive Spare Part Production. IFIP International Conference on Advances in Production Management Systems (APMS), Aug 2018, Seoul, South Korea. pp.213-221, 10.1007/978-3-319-99704-9_26. hal-02164852

\section{HAL Id: hal-02164852 \\ https://inria.hal.science/hal-02164852}

Submitted on 25 Jun 2019

HAL is a multi-disciplinary open access archive for the deposit and dissemination of scientific research documents, whether they are published or not. The documents may come from teaching and research institutions in France or abroad, or from public or private research centers.
L'archive ouverte pluridisciplinaire HAL, est destinée au dépôt et à la diffusion de documents scientifiques de niveau recherche, publiés ou non, émanant des établissements d'enseignement et de recherche français ou étrangers, des laboratoires publics ou privés. 


\title{
Scenarios for the Development of Platform-Based Networks for Additive Spare Part Production
}

\author{
Jana Frank ${ }^{1}$, Philipp Jussen ${ }^{1}$, Lennard Holst ${ }^{1}$ and Timo Lütke Meyring ${ }^{1}$ \\ ${ }^{1}$ Research Institute for Industrial Management (FIR) at RWTH Aachen, \\ Campus-Boulevard 55, 52074 Aachen
}

\begin{abstract}
The additive manufacturing technique "Selective Laser Melting" (SLM) provides the basis that is required for a fundamental paradigm shift in industrial spare part manufacturing, which affects both technological and organizational company practices. To harness the full potential of the SLM-technology with regard to agility and customizability, decentralized additive production networks need to be established. According to the principles of just in time, just in place and just enough, a global online platform that distributes construction orders to local manufacturing hubs could empower the market participants to utilize production capacities at optimal costs and minimal efforts. This work evaluates relevant fields of action by developing three future scenarios, which point out different future developments of key factors within the subject area. These scenarios enable market participants to react better and more agilely to unexpected market developments and, by doing so, make it easier for them to use the full potential of plat-form-based additive spare part production.
\end{abstract}

Keywords: Selective Laser Manufacturing, additive manufacturing, spare part production, manufacturing networks, Supply-Chain-Management

\section{Introduction}

Since introduction of additive manufacturing techniques (AM) in the 1980s, the market has been growing every year. According to recent studies, revenue in the field of 3D printing will increase from 3 billion U.S. dollars in 2013 to 10.8 billion U.S. dollars by 2021 [1]. Apart from polymer-based techniques, the process of SLM, which consists of laser-melting layers of powder material into three-dimensional elements, has become the most commonly used AM-method for manufacturing of metal components.

An interesting field of application for SLM-manufacturing is the production of industrial spare parts. According to PwC Strategy\&, more than 85 percent of spare part suppliers will have introduced AM to their businesses by 2020 [2]. Given this fundamental market shift, suppliers and customers face different challenges concerning technical maturity, copyright and market positioning. Moreover, aspects of collaboration and customization are critical for the success of an additive spare part production [2]. Current spare part production systems are predominantly organized in centralized supply chains, entailing high costs for transport activities, insufficient communication of customer needs and long delivery periods. Raising the spatial and personal proximity 
between production sites and the point of sale by producing in local additive manufacturing hubs would not only reduce logistical effort, but also result in an increased customizability. SLM-technology facilitates this process, because additive manufacturing processes enable mass customization and pave the way for an agile production planning in intelligent manufacturing systems.

The approach of decentralizing additive spare part production systems enables market participants to harness the full potential of SLM-technology. Construction orders can be distributed more cost- and time-efficiently with the help of an online platform, just in time and just in place. The research project Add2Log, subsidized by the Federal Ministry of Economics and Technology, aims to develop such a platform for decentralizing additive manufacturing, which is schematically illustrated in figure 1. To analyze potential benefits and challenges of the platform implementation, it is necessary to begin with the determination of influential parameters. So-called key factors refer to critical areas of activity, which address the challenges mentioned above and determine the success of additive manufacturing. Once key factors are selected, they can be used to create future scenarios for the development of SLM-based spare part manufacturing. These enable market participants to react with greater flexibility to certain market developments. It also makes it easier for them to create a basis for developing a corporate governance strategy.

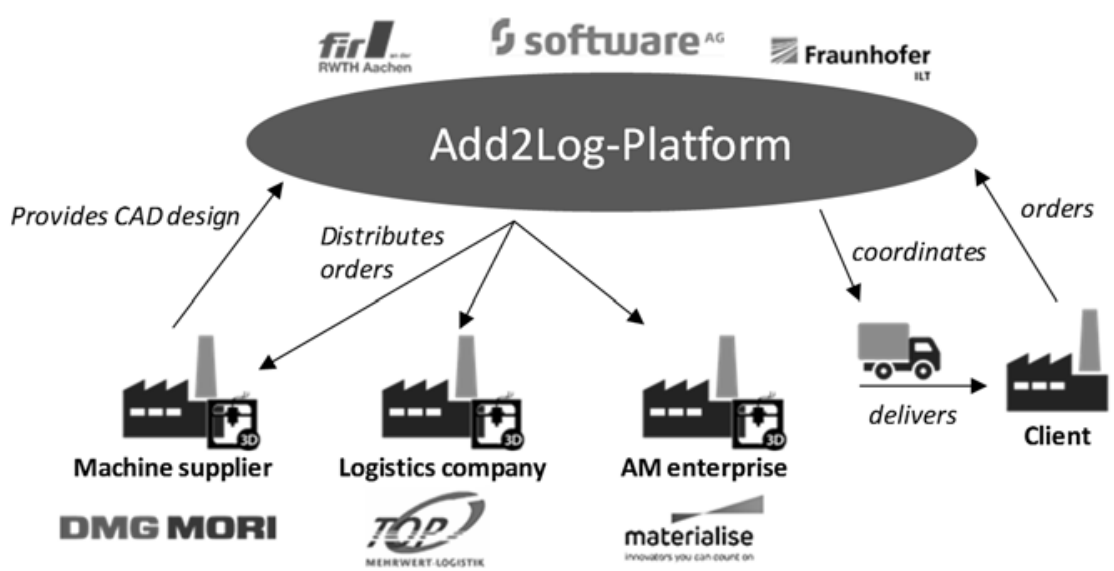

Fig. 1. Schematic illustration of the Add2Log platform for additive spare part manufacturing

\section{State of Research}

In this section, some of the scenarios currently available in scientific literature will be outlined to reveal research gaps regarding SLM-manufacturing, smart logistics and spare part production. Scenario A describes a large amount of small enterprises that use the full potential of new, inexpensive 3D printing techniques and machines to manufacture components on-demand, directly at the point of sale [3]. While distributors are being skipped in this scenario A, they play a key role in scenario B, according to which manufacturers partner with logistics companies to offer additional services. Services 
like this can be all kinds of different customization options. They are offered by the logistics company to shorten delivery times [4]. Scenario C subsequently proposes that manufacturers only provide the digital construction data, while manufacturing is outsourced to the customer. This business model focusses on data files as valuable and tradable goods, reshaping present manufacturing supply chains and branding strategies [5]. The results of this literature analysis disclose a research gap in the creation of SLMspecific scenarios for spare parts in digital networks, which is to be addressed in this work. Aspects such as material costs should be weighted differently when considering only metal-based AM-techniques. Furthermore, a focus on spare part production calls for a reconsideration of business models and quality management.

\section{$3 \quad$ Methodology}

The methodology used is called scenario analysis (see figure 2). Ute von Reibnitz describes this procedure, which is commonly used in many research fields, in great detail [6]. In this paper, the company-specific steps proposed by Reibnitz will not be taken into account, since the planned scenario analysis follows a rather holistic approach.

In a first step, the subject area, which the key factors and scenarios will refer to, is defined and demarcated thematically, temporally, and territorially. Secondly, an impact analysis is conducted to determine potential key factors, which influence the subject area significantly. The factors are evaluated during a workshop with experts from the fields of logistics and additive manufacturing. Furthermore, the results of a comprehensive literature analysis are taken into consideration. The key factors serve as parameters to characterize the situation and determine the development of the subject area by dynamically interacting with each other. Thirdly, potential development trends of the selected key factors are specified. Three development trends are specified for each factor: An optimistic, a neutral and a pessimistic one, based on literature research. This is done in order to cover every possible future development of the respective aspect. To develop consistent scenarios, the results of the trend development serve as a basis for the creation of a two-dimensional cross-impact matrix. The matrix shows the mutual influences between all the determined development trends. The program ScenarioWizard is used to calculate consistent combinations of the key factors' development trends, based on certain preconditions [7]. In a fourth step, the resulting scenarios are interpreted and used to analyze implications for a network-based additive spare part manufacturing.

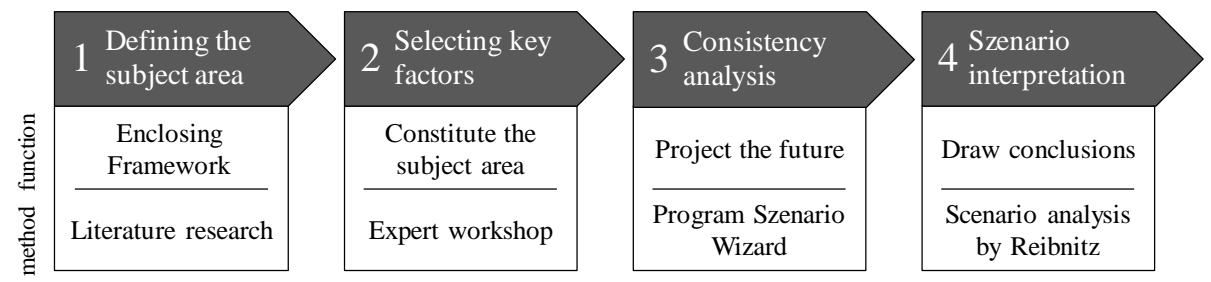

Fig. 2. Applied methodological steps from the scenario analysis [6] 


\section{$4 \quad$ Results}

\subsection{Defining the subject area}

The focus of this work is on the areas of intersection of the economic systems "additive manufacturing”, "spare part manufacturing” and "logistics”. More specifically, the key factor development focuses on the subsystem of logistics within SLM-manufacturing, considering critical fields of activity in platform-based production networks. The key factors are developed to be valid on a global scale. The time horizon for the scenario development is 10 years, as this represents a realistic time frame for the development and implementation of innovations in the field of additive manufacturing.

\subsection{Selecting key factors}

The subject area of SLM-based spare part production can be divided into a global environment, involving all external influences on the market, and a local environment that market participants have direct access to, as illustrated in figure 3.

Regarding the literature analysis, two theoretical models should be highlighted in particular: First, the PESTEL-analysis, which is used to map the global environment of SLM-based spare part production. This generally accepted model for macroeconomic analysis includes political, economic, social, technological, ecological and legal aspects [8]. Second, Ehrlenspiel list of requirements for cost-efficient product designing and is used as a starting point for modelling the challenges of product development within the local environment of SLM production. The list considers technological, human and environmental factors, including costs, time, personnel and resources [9].

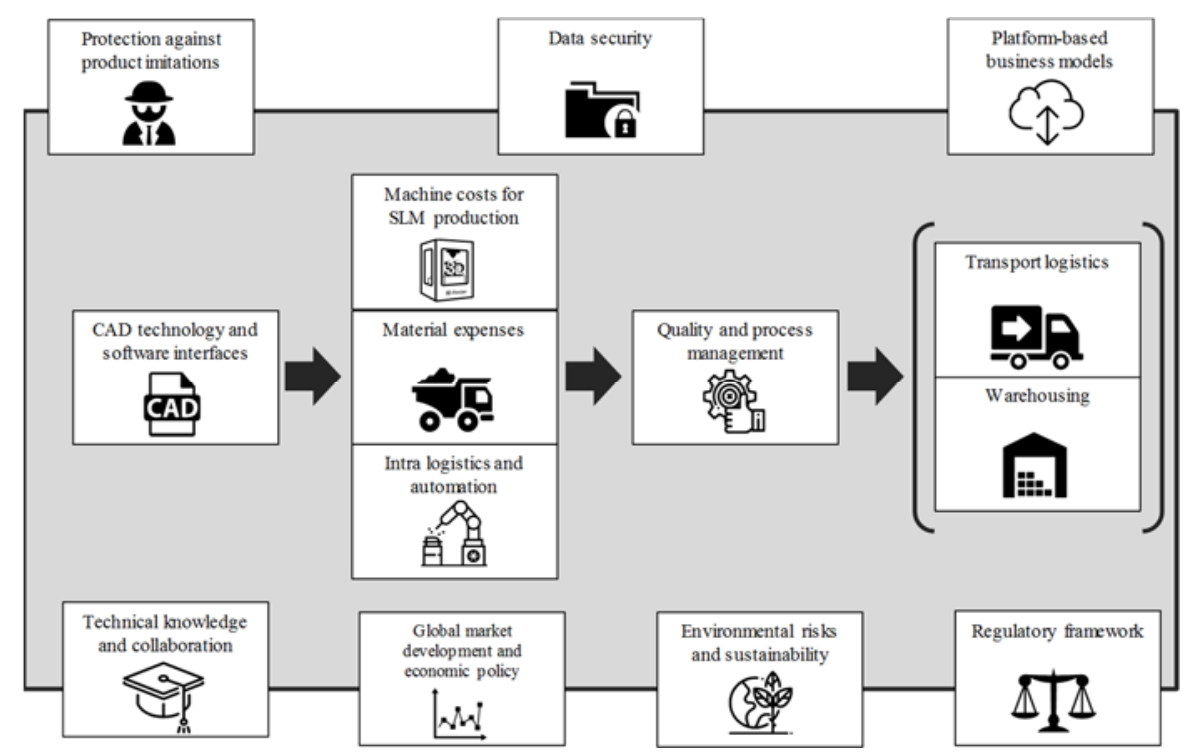

Fig. 3. Key factors for additive spare part manufacturing 
During an expert workshop, the literature-based factors were analyzed further and completed with additional influencing factors. As SLM technology has a relatively short history among additive manufacturing techniques while meeting distinctively high quality requirements, aspects regarding the structural basis of SLM-production, such as quality management, were considered particularly relevant [10]. Subsequently, 14 key factors were selected from a range of influencing factor, as shown in figure 3.

In the following, the identified key factors will be outlined and put into context. Figure 3 shows that transport logistics and warehousing play a more passive role within the subject area, which is why they will not be elucidated explicitly.

Key Factor A - CAD-design and software interfaces: Challenges for the development of CAD-software are the integration of AM-specific design opportunities into datatypes and user interfaces and the required amount of necessary technical expertise, considering the short history of SLM technology [10].

Key Factor B - Machine costs for SLM production: A large proportion of manufacturing costs relates to the acquisition and maintenance of the SLM-machinery. This key factor refers to the economic efficiency of additive manufacturing processes, interpreted as the ratio between financial and temporal costs and product quantity.

Key Factor C - Material expenses: Material costs have a major impact on manufacturing costs for SLM-components, as they must meet particularly high quality requirements. The costs are determined by size and shape, rheological properties and the degree of purity of the metallic particles [11].

Key Factor D - Intra logistics and automatization: The term intra logistics describes the organization, control and performance of the internal flow of material, flow of information and cargo handling within an industrial enterprise. Intra logistics can be comprehended as a cross-sectional task, covering the areas of materials handling, storage technology, information technology and process planning.

Key Factor E - Quality and process management: The qualification process for SLM components is based on the task areas of material, process, component and company qualification. Material qualification, the subsequent surface and heat treatment can be considered particularly crucial. Depending on the present loads, standards regarding component quality need to be established to enable product reproducibility.

Key Factor F - Platform-based business models: Platforms usually form a virtual interface and are used to connect suppliers and buyers. In the given context, service providers, logistics companies and customers are integrated into a digital ecosystem, characterized by efficient trading and a reciprocal knowledge transfer. Fraunhofer IWU classifies five major types of business models for additive manufacturing. The platform-based approach, as used by Add2Log, covers three of these types: Product individualization, manufacturing at optimal costs and minimalizing delivery times [12].

Key Factor G - Data security: Additive manufacturing currently is at risk of outpacing security infrastructure. As decentralizing additive spare part manufacturing leads to a change from physical to information logistics, data security increasingly grows in significance. This is especially true for SLM technology, which is particularly suitable for complex and highly specialized components for motorsports, aerospace or medicine industries [9]. 
Key Factor H - Global market development and economic policy: Considering the international market development, influencing the availability and pricing of metal powder materials or manufacturing machinery is crucial to determine the long-term development of additive manufacturing networks.

Key Factor I - Protection against product imitations: Because CAD files are usually sufficient for imitating a SLM-component, decentralization would make the market for SLM-based spare parts particularly vulnerable for product imitations.

Key Factor J - Regulatory framework: Many fields of technology currently experience a transformation of business models and contractual relationships. Licensing of usage rights as well as the contractual specification of required component properties and product liability must be considered.

Key Factor K - Environmental risks and sustainability: Additive manufacturing of metallic components is often associated with significant safety-related and environmental risks, especially in the case of new metallic alloys. Reactive metal powders can easily ignite or explode. With regard to $\mathrm{CO}_{2}$ emissions, a decentralization of SLMmanufacturing could shorten delivery distances and reduce logistics-related emissions.

Key Factor L - Technical knowledge and collaboration: Due to the short history of SLM technology [9], the willingness to collaborate and share data, resources and methodological know-how with others can play a key role for technological progress.

\subsection{Developing consistent future scenarios, based on development trends}

For each key factor, three future predictions are used to develop consistent future scenarios, beginning with its current state. An optimistic, a neutral and a pessimistic trend scenario mark the margins for possible future developments.

For the development of consistent scenarios on this basis, it is necessary to consider mutual influences between the development trends of all key factors. If, for example, intra logistics and automation develop according to the optimistic future trend, this will most probably have a positive effect on the development of quality and process management. To map these one-directional influences, a two-dimensional cross-impact matrix was created. This matrix serves as input for the ScenarioWizard software, which calculates all consistent combinations of development trends, following certain criteria for logical coherence. The occurrence of a non-consistent scenario is considered impossible if the chosen prerequisites, given by the cross-impact matrix, are correct. If a positive development of one key factor A is projected, which would lead to a positive development of another factor B, choosing the negative development trend for factor $\mathrm{B}$ would be inconsistent, as the external influences work towards a positive development of factor B. This is true as long as factor B is influenced by just one other key factor.

The consistency analysis, as conducted by the program ScenarioWizard, results in three scenarios with a particularly high consistency. These imply a primary positive, neutral and negative development of the subject area. However, the key factor "Protection against product imitations" shows a contrasting development compared to the remaining factors, as an intensified data transfer within a manufacturing network and a decentralized product development expectantly leads to a higher risk of imitations. 


\subsection{Scenario interpretation}

To illustrate the development trends implied by the consistent scenarios and to validate their coherence intuitively, a scenario interpretation is conducted. The respective development trends are described from a future perspective.

The first scenario will be called "New distribution of roles in the SLM value chain" and can be considered a very optimistic and therefore extreme scenario. In this scenario, SLM manufacturing takes place close to the point of sale, supported by high investments in research and development, a high degree of standardization of processes and product quality and comprehensive legal protection. Instead of specialized manufacturing enterprises, products are directly produced by logistics service providers, resulting in decentralized manufacturing clusters. These developments benefit delivery periods as well as warehousing efforts and allow spare part manufacturing at minimal time.

The second scenario "SLM technology for high wage countries" is a rather ambivalent scenario, with every key factor following the neutral development trend. Products with high quality demands are predominantly manufactured in regional production sites, which specialize in aerospace, automotive engineering or medical technology.

The third scenario "Individualization instead of mass production" implies a pessimistic development of the subject area. In this scenario, barely any agreements on software and data transfer standards can be reached and CAD software offers hardly any options regarding SLM-specific component design. Other barriers that hinder the development include rising costs of machinery and powder materials, partially resulting from international trade barriers and economic protectionism. In some cases, insufficient component quality leads to an increasing failure rate of safety-relevant products, shattering confidence in SLM-technology.

The scenario interpretation makes it clear that the factors "Platform-based business models" and "Quality and process management" are most critical when establishing a coordinating software platform. Firstly, innovative business models, such as "SLM as a service" enable a decentralized production in local manufacturing hubs, allowing an online platform to exploit the full potential of SLM technology. Secondly, sufficient quality standards and process management practices form the basis for component reproducibility and for a relationship of trust between SLM-manufacturers, as spare parts immanently have to withstand critical loads and wearing processes. Both the optimistic scenario "New role allocation in SLM value creation" and the trend scenario "SLM technology for high-wage countries" characterize an environment in which the platform, developed in the project Add2Log, has the potential to increase efficiency through an intelligent distribution of responsibilities and knowledge.

\section{$5 \quad$ Conclusion and Outlook}

This work evaluated and selected key factors and creates future scenarios for the development of platform-based networks for SLM-based spare part production. For this purpose, the selected key factors have been analyzed with regard to future developments, resulting in three future scenarios. The scenarios further enable market participants to react more agilely to unexpected market developments. In a next step, the project 
Add2Log develops new business models for all market participants in the scenario "SLM technology for high wage countries". On this basis, the Add2Log-platform can implement and thereby foster a decentralized, SLM-based spare part production throughout the manufacturing industry.

\section{Acknowledgements}

The research and development project that forms the basis for this report is funded within the scope of the "PAiCE Digitale Technologien für die Wirtschaft" technology program run by the Federal Ministry for Economic Affairs and Energy and is managed by the DLR project management agency at the German Aerospace Center in Cologne. The authors are responsible for the content of this publication.

\section{References}

1. Thiesse, F., Wirth, M., Kemper, H.-G., Moisa, M., Morar, D., Lasi, H., Piller, F., Buxmann, P., Mortara, L., Ford, S., Minshall, T.: Economic Implications of Additive Manufacturing and the Contribution of MIS. Bus Inf Syst Eng (2015). doi: 10.1007/s12599-015-0374-4

2. Geissbauer, R., Wunderlin, J., Lehr, J.: The future of spare parts is 3D. A look at the challenges and opportunities of 3D printing. https://www.strategyand.pwc.com/media/file/Thefuture-of-spare-parts-is-3D.pdf (2017). Accessed 31 March 2018

3. Thomas, O., Kammler, F., Zobel, B., Sossna, D., Zarvic, N.: Supply Chain 4.0: Revolution in der Logistik durch 3D-Druck. IM+io(1), 58-63 (2016)

4. Kuckelhaus, M., Mei Yee, P.: 3D PRINTING AND THE FUTURE OF SUPPLY CHAINS. http://www.dhl.com/content/dam/downloads/g0/about_us/logistics_insights/dhl_trendreport_3dprinting.pdf (2016). Accessed 31 March 2018

5. Jiang, R., Kleer, R., Piller, F.T.: Predicting the future of additive manufacturing: A Delphi study on economic and societal implications of 3D printing for 2030. Technological Forecasting and Social Change (2017). doi: 10.1016/j.techfore.2017.01.006

6. Reibnitz, U.: Szenario-Technik. Instrumente für die unternehmerische und persönliche Erfolgsplanung, 2nd edn. Gabler Verlag, Wiesbaden, s.l. (1992)

7. Weimer-Jehle, W.: ScenarioWizard 4.3. Constructing Consistent Scenarios Using CrossImpact Balance Analysis. ZIRIUS, University of Stuttgart. http://www.cross-impact.de/Ressourcen/ScenarioWizardManual_en.pdf (2018). Accessed 31 March 2018

8. Yüksel, I.: Developing a Multi-Criteria Decision Making Model for PESTEL Analysis. IJBM (2012). doi: 10.5539/ijbm.v7n24p52

9. Ehrlenspiel, K., Hundal, M.S., Kiewert, A., Lindemann, U. (eds.): Cost-Efficient Design. Springer-Verlag, Berlin (2007)

10. 3D fab+print: Metal-based additive manufacturing technology for professional applications (3), 10-13 (2017)

11. Bilz, M.: Selective Laser Melting. https://www.ipk.fraunhofer.de/fileadmin/user_upload/IPK_FHG/publikationen/themenblaetter/ps_ft_selective_laser_melting_en.pdf (2015). Accessed 4 April 2018

12. Lutter-Günther, M., Seidel, C., Reinhart, G., Baader, A.: Geschäftsmodelle für den Einsatz der additiven Fertigung in der industriellen Praxis (2015) 